\title{
Predicting subsurface water temperature from sea surface temperature in the Great Barrier Reef
}

\author{
$\underline{\text { R. Quinlan }}^{\mathrm{a}, \mathrm{b}}$, B. Robson ${ }^{\mathrm{c}}$ and J. Benthuysen $(\mathrm{D}) \mathrm{c}$ \\ ${ }^{a}$ James Cook University, ${ }^{b}$ AIMS@JCU, ${ }^{c}$ Australian Institute of Marine Science
}

Email:rae.quinlan@my.jcu.edu.au

\begin{abstract}
Coral reefs are at risk due to climate change, specifically extreme ocean warming events. Understanding how water temperature varies vertically in the Great Barrier Reef (GBR) lagoon is important for understanding the potential threat to coral reef ecosystems. Predictive modelling can be used to assess extreme temperature high risk areas. This study had two aims: (1) to compare vertical temperature profiles predicted by the eReefs $1 \mathrm{~km}$ resolution (GBR1) hydrodynamic model with observed temperature collected by Slocum gliders on the Great Barrier Reef (GBR); (2) to create a simple statistical regression model to quickly predict subsurface temperature on the GBR during the wet season down to $40 \mathrm{~m}$ given sea surface temperature (SST). First, profiles of eReefs and glider temperature from different regions, seasons and time of day were compared using bias, Root Mean Square Error (RMSE) and Willmott's Skill Score. Results show that temperature profiles predicted by the eReefs GBR1 hydrodynamic model are sufficiently accurate for the purpose of estimating impacts on corals. We then developed a new statistical model, Generalised Additive Modelling (GAM) was selected due to the nonlinear relationships between the subsurface temperatures and the explanatory variables. The GAM model built used five variables: SST, depth, time (days since October $1^{\text {st }}$ ) and location (as latitude and longitude) to predict temperature. The model produced RMSE values below $0.5^{\circ} \mathrm{C}$ and Pearson's correlation coefficients between predicted and observed temperatures above 0.90. This study provides a simple and accurate statistical model allowing prediction of subsurface sea temperature from observed or modelled surface temperature.
\end{abstract}

Keywords: Statistical modelling, eReefs, Generalised Additive Model 


\section{INTRODUCTION}

The ocean is warming at a disproportionately higher rate than the atmosphere, and increasing ocean temperatures are a significant threat to marine ecosystems (IPCC, 2014). The severity of thermal impacts on ocean life is well researched (Hughes et al., 2017). A large proportion of studies primarily focus on sea surface temperature, whereas the study of subsurface temperature is still growing (Akbari et al., 2017). Improving the understanding of temperature changes within the photic zone of the ocean is important for understanding the risks to marine life, which is especially vital for sessile benthic organisms because they are unable to extend their range into cooler waters (Bates et al., 2014). Coral reefs are under significant threat from increasing sea temperatures as many coral species live currently close to their upper-temperature threshold (Castillo \& Lima, 2010; Hughes et al., 2017). Therefore, prolonged periods of increased temperatures are damaging to the coral reef ecosystem, due to mortality from thermal bleaching and a reduction in recovery.

Marine heatwave (MHW) events, periods of prolonged, extremely warm ocean temperatures, have been increasing globally and are a growing field of research (Oliver et al., 2018). A consistent classification of MHWs was proposed in 2016, and in 2018, consistent naming and categorisation conventions were developed (Hobday et al., 2018). While MHW research is rapidly growing, understanding of how MHWs impact the subsurface waters is limited (Akbari et al., 2017). Short-term sea temperature extremes during the austral summer have resulted in mass coral bleaching in the Great Barrier Reef (GBR) (Hughes et al., 2017). The summers of 2015/16 and 2016/17 were the first consecutive mass bleaching events recorded on the Great Barrier Reef (Hughes et al., 2017). Increasing frequency of mass coral bleaching events are of considerable concern because it reduces the time for coral colonies to recover between events. The consecutive bleaching events showed that it is unlikely that corals can develop resilience to extreme temperature anomalies in a short time frame (Hughes et al., 2017). During the 2016/15 extreme ocean temperature event, corals down to $40 \mathrm{~m}$ were significantly bleached, resulting in a 6 percent mortality (Frade et al., 2018). In the central and northern sectors of the Great Barrier Reef, marine heatwaves had a local peak intensity in March 2016, with warm waters extending down to at least $60 \mathrm{~m}$ depth (Benthuysen, Oliver, Feng, \& Marshall, 2018). This subsurface warming highlights the need for coral reef extreme temperature studies to consider the variability of vertical temperature and the depth that MHWs can extend.

Temperature modelling for the surface and subsurface of the ocean are improving due to increasing data availability and computational power (Akbari et al., 2017). There are a wide variety of modelling methods available from simple predictive statistics to extensive machine learning. Modelling of subsurface temperature has added challenges because of the highly variable, three-dimensional nature of the water column (Akbari et al., 2017). Subsurface waters are influenced by internal tides and upwelling events which may go undetected at the surface (Benthuysen, Tonin, Brinkman, Herzfeld, \& Steinberg, 2016). Temperatures between the surface and upper five metres of the water column can vary by several degrees (Castillo \& Lima, 2010). The CSIRO eReefs hydrodynamic model was built to predict water conditions and processes in the GBR lagoon. The eReefs model can simulate conditions in hindcast, near-real-time and future scenarios (Schiller, Herzfeld, Brinkman, Rizwi, \& Andrewartha, 2015). The eReefs model is computationally expensive and runs a few days behind the present, and hence a rapid and simple predictive statistical model would be of high value in monitoring marine heatwave events.

The aims of this research are (1) to evaluate the performance of the non-data assimilating version of the eReefs $1 \mathrm{~km}$ hydrodynamic model (GBR1) by comparing the vertical temperature profiles predicted by the model with observed temperature measurements collected by Slocum gliders along the Great Barrier Reef. In addition, this study aims to (2) create a simpler and faster statistical model for predicting the subsurface temperature within the upper $40 \mathrm{~m}$ of the water column to aid coral bleaching predictions below the surface over the GBR.

\section{DATA SOURCE AND METHODS}

\section{1. eReefs hydrodynamic model}

The eReefs project is a collaboration between the CSIRO, Australian Institute of Marine Science and the Bureau of Meteorology (https://ereefs.info). eReefs is a suite of models designed to predict the hydrodynamic, biogeochemical, and sediment transport processes of the GBR. The CSIRO eReefs hydrodynamic model is built from the Sparse Hydrodynamic Ocean Code (SHOC; Herzfeld $2006^{(12)}$ ), using a curvilinear orthogonal grid. There are two resolutions of the hydrodynamic model covering the Great Barrier Reef Marine Park 
Authority management area. The first is a regional model on a $4 \mathrm{~km}$ grid (GBR4) which extends into the Coral Sea. The second is a higher resolution $1 \mathrm{~km}$ grid (GBR1) over a slightly smaller area (Figure 1). The eReefs models have 48 depth layers down to $4000 \mathrm{~m}$ depth, with increased resolution near the surface and hourly model output. The hydrodynamic model chosen for evaluation was the non-data assimilating GBR1 model, which has predictive data available from December 2014 to the present. The ouput of GBR1 was accessed through the "ereefs" package for R developed by Dr Barbara Robson (https://github.com/AIMS/ereefs). The raw output files are very large and the "ereefs" package allows the user to selectively download selected subsets of the output (eReefs model output: http://dapds00.nci.org.au/thredds/catalogs/fx3/catalog.html).

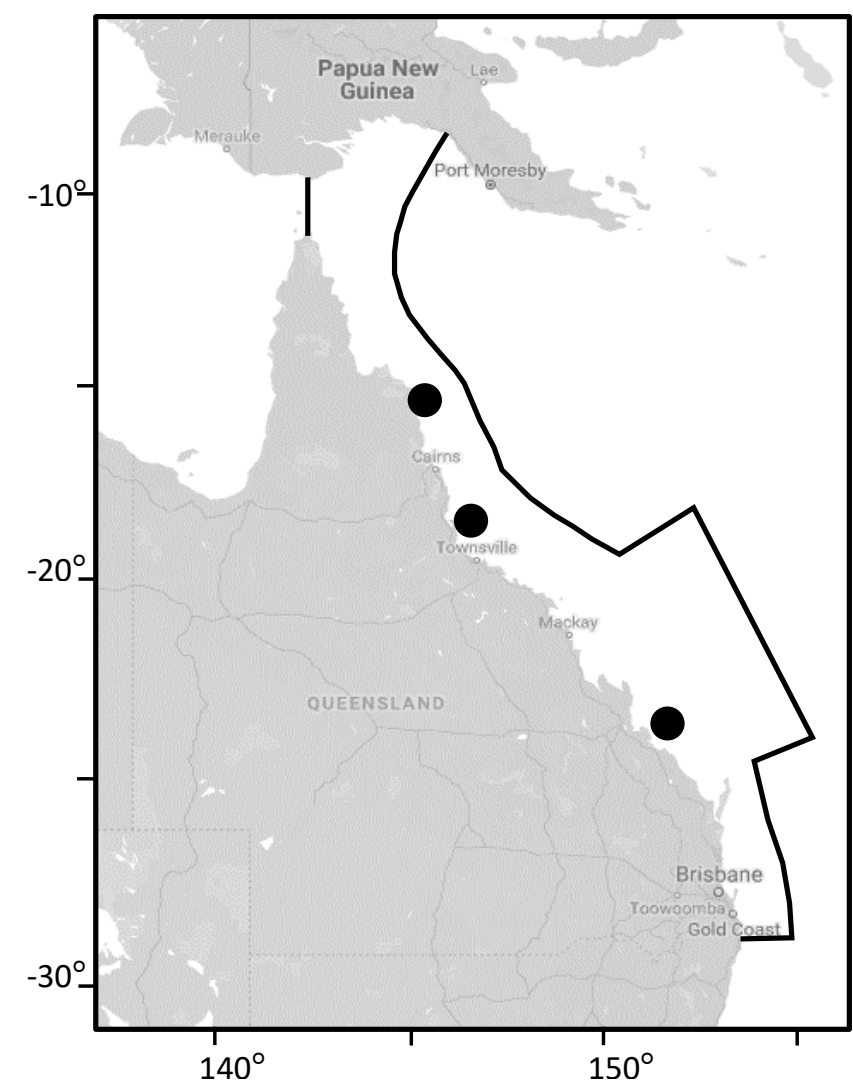

Figure 1. Map of the Queensland eastern coast, displaying the three areas that glider missions existed for the wet and dry seasons. The outline shows the coverage of the GBR1 model (modified from Google Maps).

\subsection{Slocum glider observations}

The observational data used for the model evaluation was from the Slocum glider temperature measurements, collected through the Integrated Marine Observing System (IMOS). The Slocum gliders travelled along a path in a vertical sawtooth pattern. The Slocum gliders collected data every two seconds between the surface and $200 \mathrm{~m}$ depth. Glider missions were conducted from 2015 to 2018 and were classified as north (equatorward of $\left.16^{\circ} \mathrm{S}\right)$, central $\left(16^{\circ} \mathrm{S}-20^{\circ} \mathrm{S}\right)$ or south (poleward of $20^{\circ} \mathrm{S}$ ) and as wet (October to April) or dry (May to September) seasons (Figure 1).

\subsection{Evaluation of the GBR1 model temperature predictions}

All processing and analysis were completed in RStudio with R x64 3.5.2 (RStudio Team 2015). The eReefs models and glider observations were matched in time and space and converted to the same data formats. There were 60 profiles selected, from the three regions and two seasons, and five days were sampled twice per day. The time of temperature profile observations needed to be the same as the timing of model predictions, as the eReefs model output was available on the hour. Once the data was matched temporally and spatially, the finely vertically sampled glider temperature profiles were averaged for each eReefs depth layer. The GBR1 model and glider observations were compared statistically. For each profile, the bias (difference), Root Mean Square Error (RMSE) and Willmott's Skill Score (Willmott, 1981) was calculated.

\subsection{Predictive model development}

Two predictive statistical analyses were compared: the Generalised Linear Model (GLM) and the Generalised Additive Model (GAM). From the GBR1 eReefs temperature output across four extended austral summer periods (October 1st to April 30th) between 2015 and 2019, over ten thousand randomly selected geolocations were used to develop the models. Subsurface temperatures from 8 depth layers reaching $40 \mathrm{~m}$ were obtained. Potential predictor variables included SST, location (latitude and longitude as an interaction term), time of year (days since 1 October), total water column depth and wind velocity. GLM and GAM are extensions of linear regression. GLM linear assumptions are more flexible than traditional linear regression due to incorporation of transformations, while GAM uses smoothing functions, which can be even more flexible. The packages used in R used were bigglm and mgcv, and for the GAM development and thin plate splines were used for smoothing the nonlinear factors. Best subset selection and random forest were used to explore the best model terms quantitatively. The summers starting in 2015 and 2016 were used to build the model through cross-validation. 
The extensive size of the data was computationally expensive for $\mathrm{R}$, so the data was subset into smaller workable sizes by randomly selecting subsets of the 1000 geolocations. The different models were tested against the full datasets for summers starting in 2017 and 2018. Both years were used for model testing, as early 2019 was subject to an uncharacteristically large monsoon rainfall event. The models were assessed by calculating RMSE values and Pearson correlation coefficients. The bias between the predicted and original subsurface temperatures was mapped over the entire dataset to explore patterns of deviations along the GBR.

\subsection{RESULTS AND DISCUSSION}

\subsection{Evaluation of the GBR1 model temperature predictions}

The temperature outputs from the CSIRO eReefs hydrodynamic model are sufficient for predicting single temperature profiles on the GBR. The deviation between the eReefs GBR1 hydrodynamic model profiles and glider observed profiles increased with depth (Figure 2a). The greatest average difference between the predicted and observed temperatures was in the north region, where below $10 \mathrm{~m}$ the model is underestimating the temperature by $2{ }^{\circ} \mathrm{C}$ (Figure $2 \mathrm{a}$ ). The north also had the largest differences between the surface and subsequent depths, indicating stronger thermal stratification. In the south region, where the difference between the surface and subsurface is smaller than the north, the model predicted slightly warmer temperatures (Figure 2a). The glider missions in the north were generally shallower than in the central and southern region. The depth of the mixed layer depends on several factors, thus complicating attempted predictions. External influences, such as terrestrial runoff and river plumes, wind, and, air-sea heat flux contribute to the stratification (Steinberg, 2007). In the GBR, stratification is also influenced by upwelling (e.g. Benthuysen et al. 2016), mixing around reefs, tidal currents, and low-frequency currents and eddies (Weeks, Bakun, Steinberg, Brinkman, \& Hoegh-Guldberg, 2010).
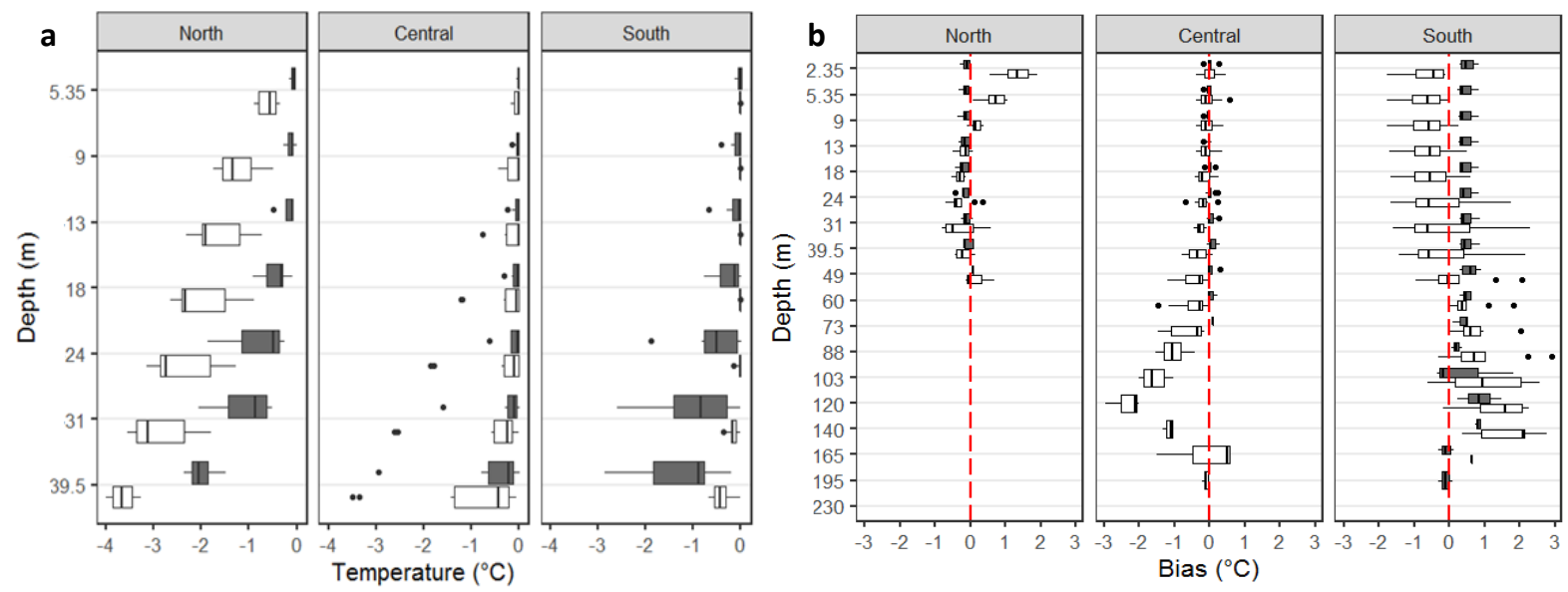

Figure 2. a) Comparison of the eReefs (open) GBR1 and Slocum glider (filled) observed temperature difference between the top $(2.35 \mathrm{~m}$ ) depth layer and each depth below for the wet season over the Great Barrier Reef's North, Central and South regions ( $n=30$ profiles). b) The boxplot of the bias (difference) between the eReefs GBR1 and Slocum glider temperature profiles in the Great Barrier Reef's North, Central and South regions, the wet (open) and dry (filled) seasons. Negative values correspond with a cooler model, positive values with a warmer model and the red dashed line indicates the zero-temperature bias ( $n=60$ profiles). The box plots show the median as the middle line within the box, the horizontal lines represent the minimum and maximum of the data, and the dots show data points outside the box (first and third quantile) by 1.5 times.

The bias between the predicted and observed temperatures, calculated for each depth layer are within $\pm 3^{\circ} \mathrm{C}$ (Figure 2b). As expected, the dry season is less vertically variable than the wet season (Figure 2b). The GBR has high interannual variability. The weather during the dry season is often stable between years; in contrast, the wet season is a time of weather extremes, including high temperatures and monsoonal rainfall (Steinberg, 2007). The variability of the seasons and thus, the variability in the accuracy of prediction is represented in the bias. Above $60 \mathrm{~m}$ depth, the average bias is within $1^{\circ} \mathrm{C}$, except for the upper $5 \mathrm{~m}$ in the northern region during the wet season, where the model is predicting warmer temperatures than observed (Figure $2 \mathrm{~b}$ ). Below $60 \mathrm{~m}$, the central and south regions have relationships between bias and depth in opposite directions (Figure 2b). The predicted temperature in the south is warmer below $60 \mathrm{~m}$, while in the central region, the predicted temperature is cooler at these depths (Figure 2b). Despite the greater bias occurring below $60 \mathrm{~m}$, there is confidence for the 
upper $40 \mathrm{~m}$ (Figure 2b). Accurate temperature predictions within the top $40 \mathrm{~m}$ are important because this is an area of ecological importance for reef-building corals (Frade et al., 2018). Therefore, the larger error below this upper mesophotic zone is not applicable for the majority of coral reefs in the GBR.

Table 1. The Root Mean Square Error (RMSE) and Willmott's Skill Score (WSS) calculated for overall temperature profile agreement between the eReefs $1 \mathrm{~km}$ hydrodynamic model (GBR1) and Slocum glider observations in the GBR North, Central and South regions and the wet and dry seasons. ( $\mathrm{n}=60$ profiles).

\begin{tabular}{llll}
\hline Region & Season & RMSE $\left({ }^{\circ} \mathbf{C}\right)$ & WSS \\
\hline North & Dry & 0.134 & 0.974 \\
& Wet & 0.056 & 0.914 \\
Central & Dry & 0.004 & 0.961 \\
& Wet & 0.384 & 0.978 \\
South & Dry & 0.472 & 0.851 \\
& Wet & 0.159 & 0.881 \\
\hline
\end{tabular}

and bottom water intrusions decouple the relaic summer months. These processes add to the complex of contribute to the increased RMSE and bias (Weeks et al., 2010). The Willmott's Skill Score is above 0.8 for all regions and seasons (Table 1). This agreement supports that the eReefs GBR1 model is adequately predicting individual temperature profiles.

\subsection{Statistical model development}

The comparisons of glider observations and the eReefs GBR1 model indicate that overall the eReefs model can sufficiently predict the temperature profiles over the GBR's continental shelf. The eReefs temperature output was selected to build predictive models to estimate the subsurface temperature down to $40 \mathrm{~m}$. eReefs was selected over observational datasets because the model can adequately predict the subsurface temperature and provide a much larger dataset, covering the entire GBR for a period of several years. The model selected is a GAM, including SST, depth, time latitude, and longitude. These model variables were selected based on a best subset selection and random forest and all the remaining explanatory factors were required for predicting temperature at a given location and time. The wind velocity and total water column depth were removed as predictors as they did not improve the model's error or explained variance. GAM was chosen over GLM because of the nonlinear relationship between the subsurface temperature and time, location (interaction term between latitude and longitude). The final model produced overall $\mathrm{RMSE}$ within $0.5^{\circ} \mathrm{C}$ (Table 2). The subsurface temperatures during the summer of 2017/8 were slightly more predictable than $2018 / 19$ based on the developed model (Table 2).

Table 2. The overall Root Mean Square Error (RMSE) and Pearson's correlation coefficient (Corr) for the Generalised Additive Model developed to predict the subsurface temperature to $40 \mathrm{~m}$ depth.

\begin{tabular}{lll}
\hline Year & RMSE & Corr \\
\hline $\mathbf{2 0 1 7 / 1 8}$ & 0.346 & 0.953 \\
$\mathbf{2 0 1 8 / 1 9}$ & 0.404 & 0.940 \\
\hline
\end{tabular}
considered here is the most extreme deviation found (Figure $3 \mathrm{~b}$ ) and there is confidence in the overall predictions during the other time periods. Accurate prediction of subsurface temperatures on the GBR is vital 
for improving the estimation of coral bleaching risk. The ability to use easily measured surface predictors makes it practical to use the model in near real time ( $\mathrm{Su}, \mathrm{Li}, \&$ Yan, 2018). This work demonstrates that in the case of the GBR continental shelf, subsurface temperature can be predicted from sea surface proxies.

\subsection{CONCLUSION}

The comparison of vertical temperatures from the eReefs GBR1 hydrodynamic model and Slocum glider measurements suggests that the eReefs model is predicting well the general trends of subsurface temperature variability at regional scales. The eReefs evaluation results affirm the confidence in eReefs as a regional-scale monitoring tool for the GBR. The ability to monitor subsurface temperature with effective and high-resolution models will help identify changes to subsurface temperature. The model developed could help identify coral reef locations at high risk to thermal stress, and therefore, identify locations where to focus monitoring efforts. By helping to identify coral reefs of concern, the use of this model could contribute to further studies aimed at understanding the impact of temperature on corals at different depths on the GBR.

The simple GAM developed in this study can rapidly and reasonably accurately predict the subsurface temperature in the GBR lagoon down to $40 \mathrm{~m}$ from surface variables. Combining the models created with existing SST forecasting and remote observation methods to predict the underlying subsurface temperatures could improve the accuracy and reliability of coral reef bleaching risk. The models could contribute to the understanding of coral bleaching risk at depth, which could aid managers in creating proactive management strategies.
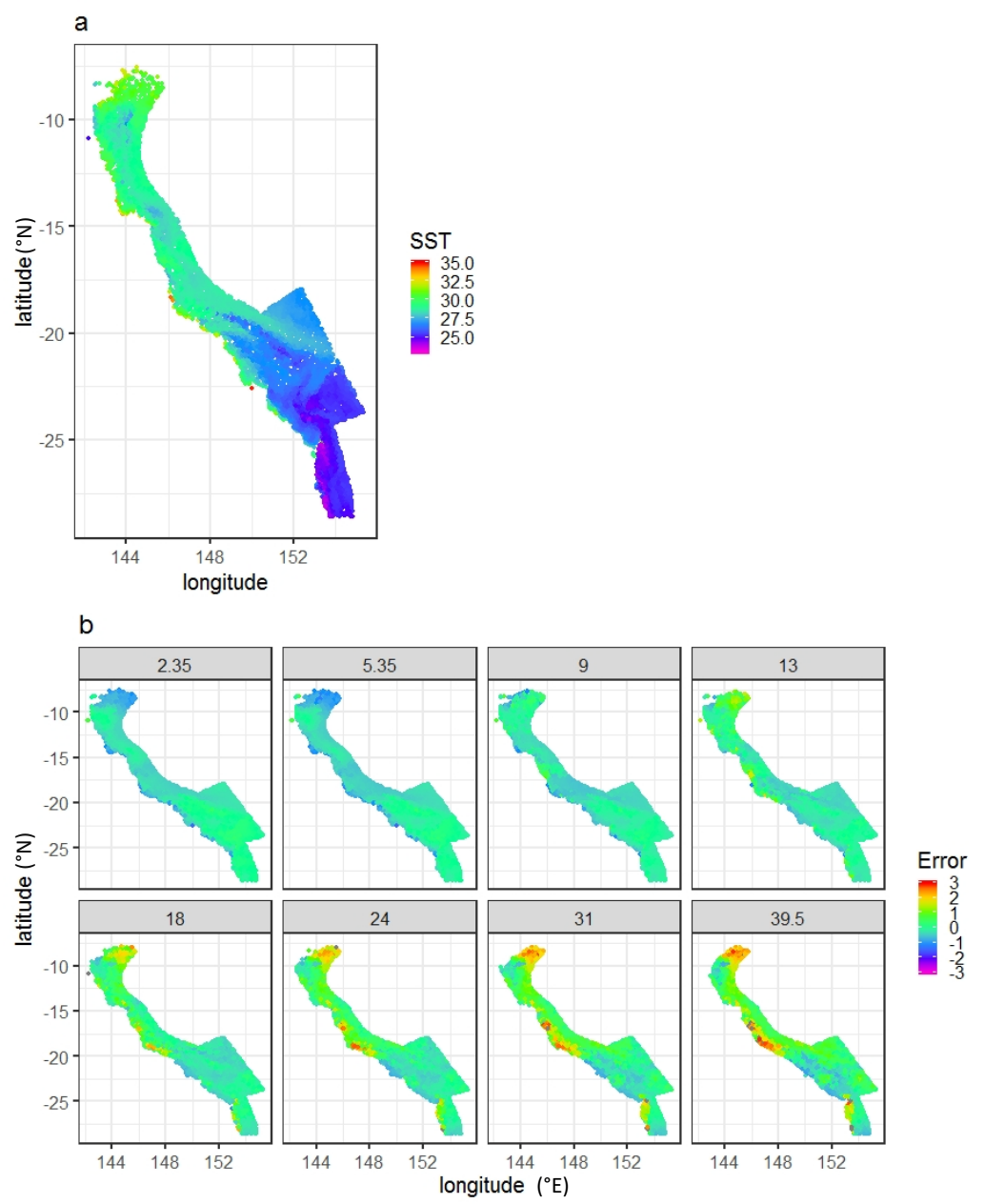

Figure 3. Map of the Great Barrier Reef during November 2018 for a) sea surface temperature from eReefs $1 \mathrm{~km}$ hydrodynamic model temperature output. b) The difference (error) between the GAM model created and the eReefs temperatures at each depth layer. A positive value indicates warm predictions, while a cool prediction is indicated by a negative value ( $\mathrm{n}=10,000$ geolocations). 


\section{ACKNOWLEDGEMENTS}

This work was completed in partial fulfilment of the requirements for a Master of Marine Science degree at James Cook University. Thank you to Dr Jon Brodie for serving on my advisory team. Data was sourced from the Integrated Marine Observing System (IMOS) - IMOS is a national collaborative research infrastructure, supported by Australian Government. Glider data are available from the Australian Ocean Data Network Portal (https://portal.aodn.org.au/). The eReefs model simulations were produced as part of the eReefs project (http://eReefs.info), a collaboration between the Science Industry Endowment Fund (SIEF), the Commonwealth Scientific Industrial Research Organisation (CSIRO), the Australian Institute of Marine Science (AIMS), the Bureau of Meteorology (BOM), and the Great Barrier Reef Foundation (GBRF), with support from BHP Billiton Mitsubishi Alliance, the Australian and Queensland governments, and with observations obtained through the Integrated Marine Observing System (IMOS).

\section{REFERENCES}

Akbari, E., Alavipanah, S. K., Jeihouni, M., Hajeb, M., Haase, D., \& Alavipanah, S. (2017). A review of ocean/sea subsurface water temperature studies from remote sensing and non-remote sensing methods. Water, 9(12).

Bates, A. E., Pecl, G. T., Frusher, S., Hobday, A. J., Wernberg, T., Smale, D. A., et al. (2014). Defining and observing stages of climate-mediated range shifts in marine systems. Global Environmental ChangeHuman and Policy Dimensions, 26, 27-38.

Benthuysen, J. A., Oliver, E. C. J., Feng, M., \& Marshall, A. G. (2018). Extreme marine warming across tropical Australia during austral summer 2015-2016. Journal of Geophysical Research-Oceans, 123(2), 1301-1326.

Benthuysen, J. A., Tonin, H., Brinkman, R., Herzfeld, M., \& Steinberg, C. (2016). Intrusive upwelling in the Central Great Barrier Reef. [Article]. Journal of Geophysical Research-Oceans, 121(11), 8395-8416.

Castillo, K. D., \& Lima, F. P. (2010). Comparison of in situ and satellite-derived (MODIS-Aqua/Terra) methods for assessing temperatures on coral reefs. Limnology and Oceanography-Methods, 8, 107117.

Frade, P. R., Bongaerts, P., Englebert, N., Rogers, A., Gonzalez-Rivero, M., \& Hoegh-Guldberg, O. (2018). Deep reefs of the Great Barrier Reef offer limited thermal refuge during mass coral bleaching. Nature Communications, 9.

Herzfeld, M. (2006). An alternative coordinate system for solving finite difference ocean models. Ocean Modelling, 14(3-4), 174-196.

Hobday, A. J., Oliver, E. C. J., Sen Gupta, A., Benthuysen, J. A., Burrows, M. T., Donat, M. G., et al. (2018). Categorizing and naming marine heatwaves. Oceanography, 31(2), 162-173.

Hughes, T. P., Kerry, J. T., Alvarez-Noriega, M., Alvarez-Romero, J. G., Anderson, K. D., Baird, A. H., et al. (2017). Global warming and recurrent mass bleaching of corals. Nature, 543(7645), 373-377.

IPCC. (2014). Climate Change 2014: Synthesis Report. Contribution of Working Groups I, II and III to the Fifth Assessment Report of the Intergovernmental Panel on Climate Change. Geneva, Switzerland.

Oliver, E. C. J., Donat, M. G., Burrows, M. T., Moore, P. J., Smale, D. A., Alexander, L. V., et al. (2018). Longer and more frequent marine heatwaves over the past century. Nature Communications, 9.

Schiller, A., Herzfeld, M., Brinkman, R., Rizwi, F., \& Andrewartha, J. (2015). Cross-shelf exchanges between the Coral Sea and the Great Barrier Reef lagoon determined from a regional-scale numerical model. Continental Shelf Research, 109, 150-163.

Steinberg, C. (2007). Chapter 3 Impacts of climate change on the physical oceanography of the Great Barrier Reef. Australia: Great Barrier Reef Marine Park Authority and Australian Greenhouse Office.

Su, H., Li, W. E., \& Yan, X. H. (2018). Retrieving temperature anomaly in the global subsurface and deeper ocean from satellite observations. Journal of Geophysical Research-Oceans, 123(1), 399-410.

Weeks, S. J., Bakun, A., Steinberg, C. R., Brinkman, R., \& Hoegh-Guldberg, O. (2010). The Capricorn Eddy: a prominent driver of the ecology and future of the southern Great Barrier Reef. Coral Reefs, 29(4), 975-985.

Willmott, C. J. (1981). On the validation of models. Physical geography, 2(2), 184-194. 